\title{
Single nucleotide polymorphisms in TNF are associated with susceptibility to aspirin-exacerbated respiratory disease but not to cytokine levels: a study in Mexican mestizo population
}

\author{
Gandhi F Pavón-Romero 1,2,3, Juan M Reséndiz-Hernández ${ }^{1,2,3}$, Fernando \\ Ramírez-Jiménez ${ }^{1,2,3}$, Gloria Pérez-Rubio ${ }^{1,2,3}$, Ángel Camarena ${ }^{1,2,3}$, Luis M Terán ${ }^{*} 1$ \& \\ Ramcés Falfán-Valencia**,2 \\ ${ }^{1}$ Department of Allergy \& Clinical Immunology, Instituto Nacional Enfermedades Respiratorias Ismael Cosío Villegas, Tlalpan 4502, \\ Sección XVI, Tlalpan, 14080, Mexico City, Mexico \\ ${ }^{2}$ HLA Laboratory, Instituto Nacional de Enfermedades Respiratorias Ismael Cosío Villegas, Tlalpan 4502, Sección XVI, Tlalpan, \\ 14080, Mexico City, Mexico \\ ${ }^{3}$ Biomedicine In the Post-Genomic Era, Tlalpan 4502, Sección XVI, Tlalpan, 14080, Mexico City, Mexico \\ * Author for correspondence: Tel.: +52 5554871700 ext. 5259; Fax: +52 555587 1740; Imteran@iner.gob.mx \\ ** Author for correspondence: Tel.: +52 5554871700 ext. 5152; rfalfanv@iner.gob.mx
}

\begin{abstract}
Aim: To evaluate the association of three single nucleotide polymorphisms in TNF and one in LTA in Mexican patients with aspirin-exacerbated respiratory disease (AERD) and the correlation of those single nucleotide polymorphisms with serum levels of TNF- $\alpha$. Patients \& methods: Case-control study including 133 patients with AERD, 135 patients with asthma (aspirin-tolerant asthmatics) and 182 healthy subjects. Results: GA genotype of rs1800629 in TNF was found to be associated with the risk of developing AERD $(p<0.05$; odds ratio $=2.36)$ and by dominant model $(p<0.05$; odds ratio $=2.51)$. Furthermore, there was a difference in the serum levels between the aspirin-tolerant asthmatics group and the other groups ( $p<0.001)$. Conclusion: The GA genotype of $r s 1800629$ is associated with genetic susceptibility to AERD, but it does not correlate to protein serum levels.
\end{abstract}

First draft submitted: 9 May 2017; Accepted for publication: 5 September 2017; Published online: 27 November 2017

Keywords: AERD • aspirin $\bullet$ asthma $\bullet$ genetic susceptibility $\bullet$ TNF

Aspirin-exacerbated respiratory disease (AERD) is a clinical disease characterized by hypersensitivity to aspirin, asthma and chronic rhinosinusitis with nasal polyps. It affects $10 \%$ of the population with asthma; however, its prevalence increases to $21 \%$ when provocation tests are used [1]. AERD is a disease characterized by restructuring of the airway [2] and the presence of extensive hyperplastic eosinophilic sinusitis with the formation of nasal polyps [3]. The most important clinical characteristic is bronchoconstriction after the administration of aspirin (ASA) or other nonsteroidal anti-inflammatory drugs (NSAIDs) [2,4]. The physiopathology involves a block in the cyclooxygenase pathway that promotes a diversion of arachidonic acid metabolism toward the lipoxygenase pathway, inducing the synthesis of leukotrienes such as LTC4, LTD4 and LTE4 [5,6], proteins that induce inflammatory cell chemotaxis, and the release of cytokines such as TNF- $\alpha$ [7] and lymphotoxin. TNF- $\alpha$ is a critical molecule in the regulation of inflammation because it induces a cascade of other inflammatory cytokines, chemokines and growth factors [8]. The results of various in vivo and in vitro studies indicate that the increase in their production is involved in the severity of the inflammation, due to their participation in restructuring the airway and in the pro-oxidative response [9]. In relation to single nucleotide polymorphisms (SNPs), it has been reported that rs $1800629(\mathrm{G} \rightarrow \mathrm{A}$ change in position -308) increases transcriptional activity [10,11], in addition to being associated with different pulmonary pathological diseases such as chronic obstructive pulmonary disease and asthma $[9,12,13]$. However, no SNPs have been reported in TNF or LTA that are associated with AERD.

Future $\%$ Medicine 


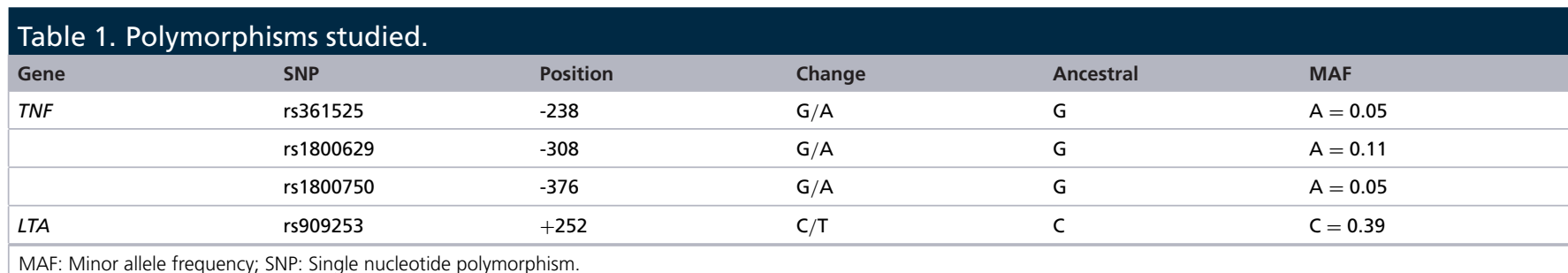

\section{Patients \& methods}

\section{Study population}

Participants with ancestry of at least two generations born in Mexico were included. Patients with AERD ( $\mathrm{n}=133)$ and aspirin-tolerant asthmatics (ATA; $\mathrm{n}=135$ ) were recruited from the clinical immunology and allergy department of the Ismael Cosío Villegas National Institute of Respiratory Diseases (Instituto Nacional de Enfermedades Respiratorias Ismael Cosio Villegas [INER]). The healthy control (HC) group $(\mathrm{n}=182)$ was composed of subjects who presented negative for asthma or AERD in the clinical evaluation and diagnostic tests. The patients were given methacholine challenge tests and nasal provocation tests with lysine-aspirin (L-ASA). Only patients with AERD should test positive after an L-ASA challenge or have bronchospasm that would require intubation after ingesting ASA or NSAIDs. After the clinical phenotyping, a blood sample was extracted from all participants via venipuncture for the quantification of eosinophils and IgE and DNA extraction. The study was approved by the science and bioethics committee of INER (protocol B14-12), and informed consent was obtained from all participants.

\section{Methacholine challenge}

The methacholine challenge was conducted according to the guidelines established by the American Thoracic Society [14]. Spirometry was performed using a flowscreen spirometer (Jaeger Carefusion, Hoechberg, Germany) programmed with the reference values for Mexicans obtained by Pérez-Padilla et al. [15]. Before basal spirometry, the participant was aerosolized with a saline solution of $0.9 \%$ for $20 \mathrm{~s}$ and subsequently aerosolized with methacholine at concentrations of $0.03-32 \mathrm{mg}$. Between each concentration, spirometry was conducted with the objective of identifying the concentration of methacholine that would provoke a decrease of $20 \%$ of forced expiratory volume in $1 \mathrm{~s}$, and then, the PC20 value was calculated according to the formula accepted by the American Thoracic Society. This result was categorized in four classes (severe, moderate, light and without evidence of bronchial hyper-reactivity) [14].

\section{Nasal provocation test with L-ASA}

The nasal provocation test with L-ASA was developed according to the guidelines established by the European Academy of Allergy and Clinical Immunology/Global Allergy and Asthma European Network (EAACI/GA2LEN) [16], with the test considered positive if there was a decrease of $\geq 40 \%$ in the total basal nasal flow and the presence of clinical symptoms after the administration of L-ASA. Both studies were conducted independently.

\section{SNP selection}

Three SNPs in TNF and one in $L T A$ were selected that had been previously reported in inflammatory respiratory diseases and had an allele frequency $\geq 5 \%$. The genetic data for each polymorphism are described in Table 1.

\section{Genotyping}

The DNA was extracted from peripheral blood cells, obtained through venipuncture; the genomic DNA was obtained using the commercial BDtract DNA isolation kit (Maxim Biotech, CA, USA). The genetic material was quantified by ultraviolet light absorption spectrophotometry at a wavelength of $260 \mathrm{~nm}$, using a nanodrop kit (Thermo Scientific, DE, USA). Contamination with organic compounds and proteins was determined by establishing the relationship of the 260/240 and 260/280 readings, respectively; the samples were considered free of contaminants when, in both cases, the ratio was 1.7-2.0. The allele discrimination of the SNPs was conducted using Taqman commercial probes (Applied Biosystems, CA, USA) at concentrations of $20 \times$, using the PCR 
Table 2. Clinical and demographic characteristics.

\begin{tabular}{|c|c|c|c|c|c|c|}
\hline Variable & AERD, $n=133$ & ATA, $\mathrm{n}=135$ & $H C, n=182$ & $\begin{array}{l}\text { p-value (AERD versus } \\
\text { HC) }\end{array}$ & $\begin{array}{l}\text { p-value (ATA versus } \\
\text { HC) }\end{array}$ & $\begin{array}{l}\text { p-value (AERD versus } \\
\text { ATA) }\end{array}$ \\
\hline $\operatorname{Sex}(M / F)$ & $1 / 1.5$ & $1.3 / 1$ & $1 / 1.4$ & NS & 0.01 & 0.01 \\
\hline Age (years) & $42.3 \pm 12.1$ & $42.6 \pm 14.2$ & $43 \pm 13.2$ & NS & NS & NS \\
\hline $\mathrm{FEV}_{1}(\%)$ & $98 \pm 14.0$ & $101 \pm 15.4$ & $103 \pm 12.5$ & NS & NS & NS \\
\hline PC20 severe (\%) & 24 & 59 & 0 & NA & NA & 0.003 \\
\hline $\begin{array}{l}\text { TN flow prechallenge } \\
(\mathrm{mm} / \mathrm{l})\end{array}$ & $674 \pm 98$ & $653 \pm 70$ & $803 \pm 97$ & 0.001 & 0.001 & NS \\
\hline $\begin{array}{l}\text { TN flow } \\
\text { postchallenge }(\mathrm{mm} / \mathrm{l})\end{array}$ & $404 \pm 59$ & $587 \pm 63$ & $763 \pm 92$ & 0.001 & 0.001 & 0.001 \\
\hline TN flow change (\%) & 40.1 & 10.1 & 3.7 & NA & NA & NA \\
\hline Eosinophils (\%) & $4.89 \pm 4.11$ & $3.89 \pm 5.48$ & $1.59 \pm 8.3$ & 0.001 & 0.001 & NS \\
\hline $\operatorname{lgE}(\mathrm{IU} / \mathrm{ml})$ & $212 \pm 368$ & $343 \pm 145$ & $107 \pm 55$ & 0.001 & 0.001 & 0.05 \\
\hline TNF- $\alpha$ & $1.34 \pm 0.54$ & $2.60 \pm 1.76$ & $1.73 \pm 1.56$ & NS & 0.001 & 0.001 \\
\hline
\end{tabular}

technique in real time mode (quantitative PCR) on 7300 Real Time PCR Systems equipment (Applied Biosystems) and analyzed using Sequence Detection Software version 1.4 .

Protein quantification of TNF- $\alpha$

Detection of the serum levels was performed using the ELISA technique with the commercial human TNF- $\alpha$ ELISA development kit (PeproTech, NJ, USA) at a wavelength of $405 \mathrm{~nm}$ with a correction by subtraction to $650 \mathrm{~nm}$ on I-mark equipment (BioRad, Tokyo, Japan). The results were analyzed using Microplate Manager System Software v.6.1 (BioRad), establishing a semilogarithmic curve, which was rendered in parallel, establishing values from 0 to $2 \mathrm{ng} / \mathrm{ml}$. The limits of detection established were $0.2 \mathrm{ng} / \mathrm{ml}$ for the lower limit and $2.2 \mathrm{ng} / \mathrm{ml}$ for the upper limit; the results obtained are expressed in nanogram per milliliter.

\section{Statistical analysis}

The statistical analysis was conducted comparing the groups as follows: AERD versus ATA, AERD versus HC and ATA versus HC. For the quantitative clinical variables, means analysis was performed; for the qualitative variables, frequency analysis was used. The statistical significance was established using SPSS version 20 (IBM, NY, USA) and Epi Info 7.2.1.0 (Division of Health Informatics \& Surveillance, GA, USA). The results were considered significant when the p-value was $<0.05$; similarly, the odds ratio $(\mathrm{OR})>1$ was estimated with a CI of $95 \%$.

\section{Results}

In the study, 133 patients with AERD, 135 patients with aspirin-tolerant asthma and 182 control group subjects participated. The clinical and demographic data are presented in Table 2 . The male/female ratio was 1 man for every 1.5 women in the AERD group, which was similar in the control subjects and inverted among the asthmatics. The age of the subjects included in the study was approximately 43 years. The percentages of eosinophils in the AERD and ATA groups were statistically greater than that in the control group $(p<0.001)$. In relation to the serum levels of IgE, the group of patients with asthma presented a greater concentration compared with those of the control group (AERD vs HC [p < 0.01]; ATA vs HC [p < 0.01]), and there was also a difference between the AERD versus ATA $(\mathrm{p}<0.05)$ groups. The forced expiratory volume in $1 \mathrm{~s}$ of all the participants was found to be within the expected parameters of each group; however, the severity of bronchial hyper-reactivity, categorized using the PC20, was greater in the patients with ATA compared with those with AERD $(p=0.003)$. The greatest levels of total nasal flow were presented by the HC group; nevertheless, after L-ASA administration, there was a mean decrease of $40 \%$ only in the AERD group.

\section{Association with alleles \& genotypes}

Four SNPs were genotyped in two genes: three in TNF (rs361525, rs1800629 and rs1800750) and one in LTA (rs909253); the results of the allele and genotype frequencies are shown in Table 3. The four polymorphisms 
Preliminary Communication Pavón-Romero, Reséndiz-Hernández, Ramírez-Jiménez et al.

\begin{tabular}{|c|c|c|c|c|c|c|c|c|c|c|}
\hline \multirow[t]{2}{*}{ Gene/SNP } & \multirow{2}{*}{$\begin{array}{l}\text { Genotype/ } \\
\text { allele }\end{array}$} & \multicolumn{2}{|c|}{ AERD } & \multicolumn{2}{|c|}{ ATA } & \multicolumn{2}{|c|}{$\mathrm{HC}$} & \multirow[t]{2}{*}{$p$-value } & \multirow[t]{2}{*}{ OR } & \multirow[t]{2}{*}{$95 \% \mathrm{Cl}$} \\
\hline & & $n=133$ & FG (\%) & $n=135$ & FG (\%) & $n=182$ & FG (\%) & & & \\
\hline \multicolumn{11}{|l|}{ TNF } \\
\hline \multirow[t]{5}{*}{ rs361525 } & GG & 115 & 86.47 & 125 & 92.59 & 168 & 92.31 & & & \\
\hline & GA & 17 & 12.78 & 9 & 6.67 & 14 & 7.69 & & & \\
\hline & AA & 1 & 0.75 & 1 & 0.74 & 0 & 0.00 & & & \\
\hline & G & 247 & 92.85 & 259 & 95.92 & 350 & 96.15 & & & \\
\hline & A & 19 & 7.14 & 11 & 4.07 & 14 & 3.84 & & & \\
\hline \multirow[t]{5}{*}{ rs1800629 } & GG & 113 & 84.96 & 119 & 88.15 & 170 & 93.41 & & & \\
\hline & GA & 19 & 14.29 & 14 & 10.37 & 12 & 6.59 & $0.038^{\dagger}$ & 2.38 & $1.11-5.09$ \\
\hline & AA & 1 & 0.75 & 2 & 1.48 & 0 & 0.00 & & & \\
\hline & $\mathrm{G}$ & 245 & 92.10 & 252 & 93.33 & 352 & 96.70 & & & \\
\hline & $\mathrm{A}$ & 21 & 7.89 & 18 & 6.66 & 12 & 3.29 & $0.017^{\dagger}$ & 2.51 & $1.15-5.71$ \\
\hline \multirow[t]{5}{*}{ rs 1800750} & GG & 124 & 93.23 & 130 & 96.29 & 167 & 91.76 & & & \\
\hline & GA & 8 & 6.02 & 5 & 3.80 & 12 & 6.59 & & & \\
\hline & AA & 1 & 0.75 & 0 & 0.00 & 3 & 1.65 & & & \\
\hline & $\mathrm{G}$ & 256 & 96.24 & 259 & 95.92 & 346 & 95.05 & & & \\
\hline & A & 10 & 3.75 & 11 & 4.07 & 18 & 4.94 & & & \\
\hline \multicolumn{11}{|l|}{ LTA } \\
\hline \multirow[t]{5}{*}{ rs909253 } & GG & 62 & 46.62 & 61 & 45.19 & 80 & 43.96 & & & \\
\hline & GA & 58 & 43.61 & 60 & 44.44 & 84 & 46.15 & & & \\
\hline & $A A$ & 13 & 9.77 & 14 & 10.37 & 18 & 9.89 & & & \\
\hline & A & 182 & 68.42 & 182 & 67.40 & 244 & 67.03 & & & \\
\hline & G & 84 & 31.57 & 88 & 32.59 & 120 & 32.96 & & & \\
\hline
\end{tabular}

evaluated were found in Hardy-Weinberg equilibrium, $\mathrm{p}=0.64$

To determine the possible associations between the analyzed polymorphisms, the allele and genotype frequencies were analyzed between both groups using the $\chi^{2}$ test. Using the codominant model, a statistically significant difference was found for the GA genotype of rs1800629 between the groups AERD versus HC ( $\mathrm{p}<0.05$; $\mathrm{OR}=2.38 ; 95 \% \mathrm{CI}=1.11-5.09)$. Consistent with this finding, the A allele of the same SNP was found to be associated with susceptibility to AERD ( $\mathrm{p}<0.05$; OR $=2.51 ; 95 \% \mathrm{CI}=1.12-5.71$ ).

Additionally, the genotype frequency analysis was conducted using the dominant model of the studied groups, establishing the sums of the heterozygotes and homozygotes for the minor allele compared with the common genotype; in this way, a statistically significant difference was found for the same SNP in TNF, rs1800629, when comparing AERD versus $\mathrm{HC}(\mathrm{p}=0.023$; $\mathrm{OR}=2.51 ; 95 \% \mathrm{CI}=1.17-5.33$; Table 4). Similarly, an analysis using the recessive model was conducted; however, no differences were identified between the groups for any of the SNPs studied (Supplementary Table 1).

Haplotype analysis was conducted for the SNPs in both genes and the three comparisons; however, in our population, no linkage disequilibrium was reported $\left(r^{2}=0.53\right.$; Figure 1$)$.

\section{Determination of TNF- $\alpha$ serum values}

In the determination of the serum values of TNF- $\alpha$, statistically significant differences were observed between AERD versus ATA $(\mathrm{p}<0.001)$ and ATA versus HC ( $\mathrm{p}<0.001)$ but not between AERD versus HC (Figure 2$)$. When stratifying rs 1800629 by genotypes GA versus GG between the study groups, no difference was detected in the cytokine levels.

\section{Discussion}

The objective of this study was to identify SNPs in $T N F$ and $L T A$ that are associated with susceptibility to AERD, as well as the correlation between TNF serum levels and the severity of the disease. We found that the GA genotype 

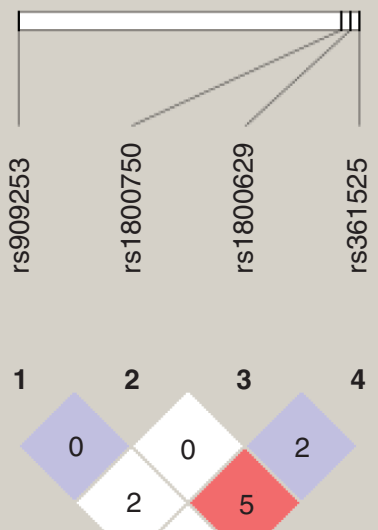

0

(A)

(B)
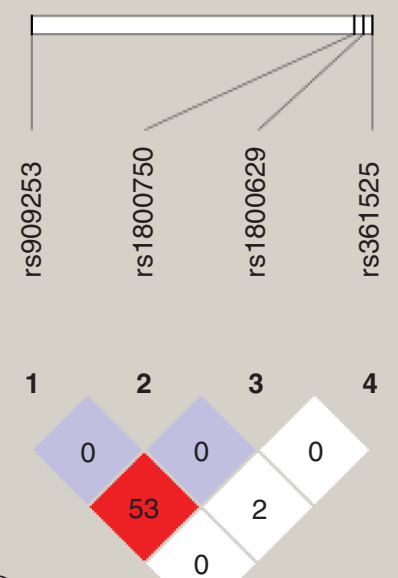

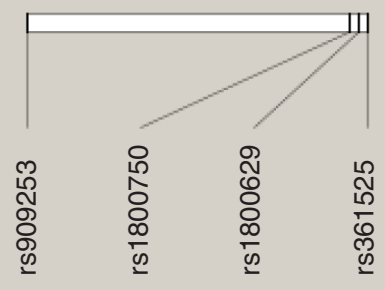

1

2

\section{3}

4

0

6

3

(C)

Figure 1. Haplotype analysis. (A) AERD versus ATA; (B) AERD versus HC; (C) ATA versus HC.

AERD: Aspirin-exacerbated respiratory disease, ATA: Aspirin-tolerant asthmatic; HC: Healthy control.

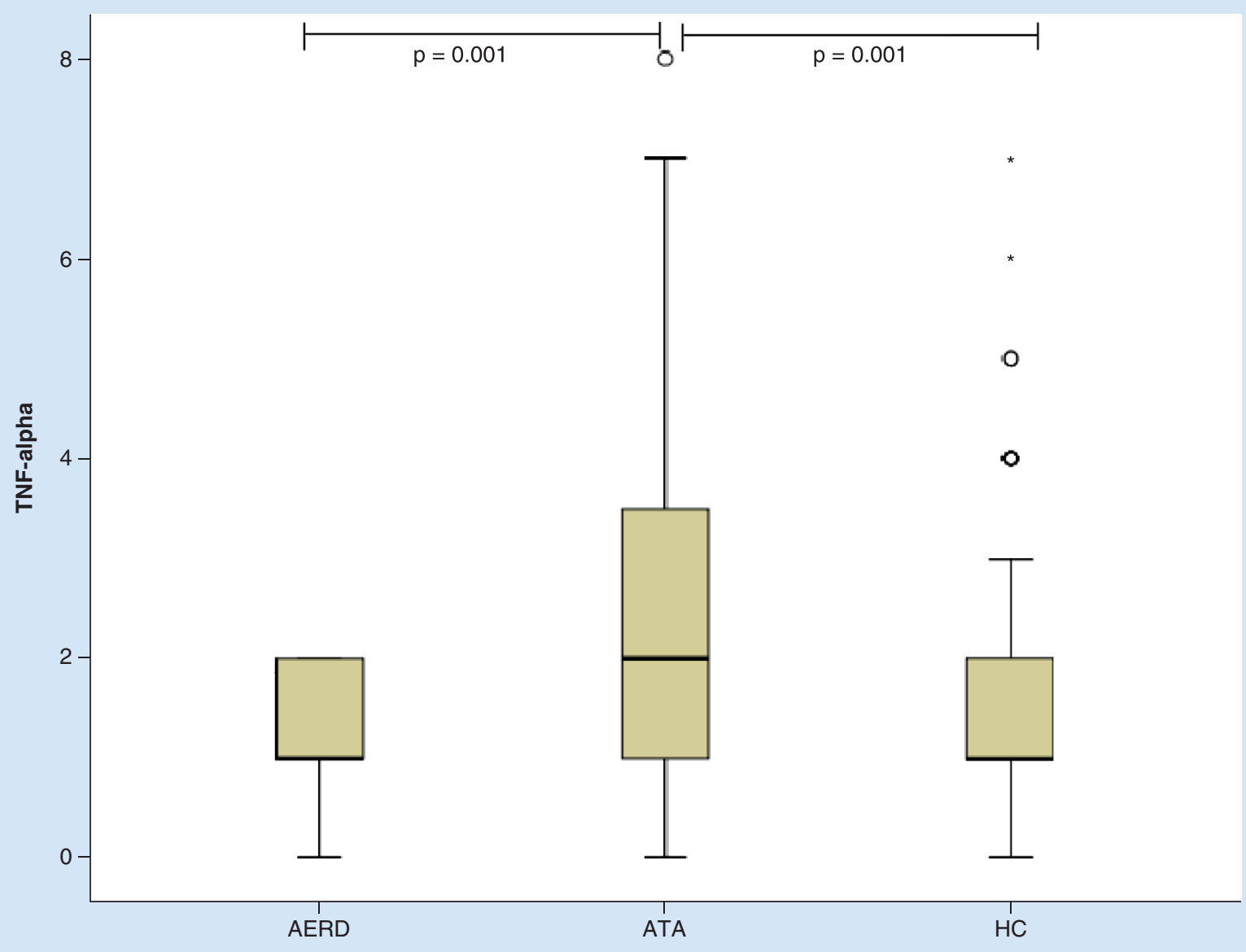

Figure 2. Comparison of serum levels of TNF- $\alpha$ among groups. Significant difference in the serum levels of TNF- $\alpha$ between the AERD versus ATA $(p<0.001)$ and ATA versus HC $(p<0.001)$ groups.

AERD: Aspirin-exacerbated respiratory disease; ATA: Aspirin-tolerant asthmatic; HC: Healthy control. 


\begin{tabular}{|c|c|c|c|c|c|c|c|c|c|c|}
\hline \multirow[t]{2}{*}{ Gene/SNP } & \multirow[t]{2}{*}{ Genotype } & \multicolumn{2}{|c|}{ AERD } & \multicolumn{2}{|c|}{ ATA } & \multicolumn{2}{|c|}{$\mathrm{HC}$} & \multirow[t]{2}{*}{ p-value } & \multirow[t]{2}{*}{ OR } & \multirow[t]{2}{*}{$95 \% \mathrm{Cl}$} \\
\hline & & $n=133$ & FG (\%) & $n=135$ & FG (\%) & $n=182$ & FG (\%) & & & \\
\hline \multicolumn{11}{|l|}{$T N F$} \\
\hline \multirow[t]{2}{*}{ rs361525 } & GG & 115 & 86.48 & 125 & 92.59 & 168 & 92.30 & & & \\
\hline & $\mathrm{GA}+\mathrm{AA}$ & 18 & 13.53 & 10 & 7.40 & 14 & 7.69 & & & \\
\hline \multirow[t]{2}{*}{ rs1800629 } & GG & 113 & 84.96 & 119 & 88.14 & 170 & 93.40 & & & \\
\hline & $\mathrm{GA}+\mathrm{AA}$ & 20 & 15.03 & 16 & 11.85 & 2 & 6.59 & $0.023^{\dagger}$ & 2.51 & $1.17-5.33$ \\
\hline \multirow[t]{2}{*}{ rs1800750 } & GG & 124 & 93.23 & 130 & 96.29 & 167 & 91.75 & & & \\
\hline & $\mathrm{GA}+\mathrm{AA}$ & 9 & 6.76 & 5 & 3.70 & 15 & 8.24 & & & \\
\hline \multicolumn{11}{|l|}{ LTA } \\
\hline \multirow[t]{2}{*}{ rs909253 } & GG & 62 & 46.61 & 61 & 45.18 & 80 & 43.95 & & & \\
\hline & $\mathrm{GA}+\mathrm{AA}$ & 71 & 53.38 & 74 & 54.81 & 102 & 56.04 & & & \\
\hline
\end{tabular}

of rs1800629 is associated with genetic susceptibility to AERD, but it is independent of protein serum levels; interestingly, TNF- $\alpha$ serum levels were increased in the patient group of ATA compared with both the control and AERD groups.

This study was conducted with mestizo Mexican patients with AERD, which is a disease underdiagnosed by frontline healthcare in Mexico; therefore, there are no official epidemiological reports of its prevalence. Nevertheless, in the National Institute of Respiratory Diseases (Instituto Nacional de Enfermedades Respiratorias), which is the national center of reference for respiratory disease diagnosis and control, it has been estimated that intolerance to NSAIDs is approximately $8 \%$. This is a lower data that previously reported by Jenkins et al. [1]; however, the patients' clinical characteristics are similar to those described by Szcezclick in an Eastern European population [17]. Nevertheless, the Mexican population presents distinct characteristics compared with those of the Asian population, such as a lower concentration of IgE [18] and higher concentration of eosinophils in the blood [4].

In previous studies, Li et al. reported that the genotype GA in TNF-308 (rs1800629) was associated with conditions in a Caucasian population that alter the severity of asthma, such as the presence of an asthmatic crisis and lack of control over symptoms [19]. This finding is consistent with the results reported by Fuertes et al., who describe the association of an A allele of rs 1800629 with an increased risk of developing allergic rhinitis in Caucasian infants [20]. In the Mexican population, Jiménez-Morales et al. associated the A allele of the same SNP with asthma in pediatric patients of the female sex [21]. In the present study, this allele was not associated with risk if comparing the ATA versus $\mathrm{HC}$ group; however, when contrasting the AERD versus $\mathrm{HC}$ groups, there was an association with risk, with the GA genotype being shown to be increased in the AERD group compared with the HC group. These results are the first to associate the GA genotype of rs1800629 with genetic susceptibility to AERD. Previously, in Mexican mestizo population, it has been reported that the AA genotype of rs16944 in IL1B is associated with susceptibility to AERD when comparing AERD patients with ATAs [22].

At the functional level, it has been reported that the A allele of rs1800629 increases the transcriptional rate of the gene $[10,23,24]$; additionally, this same polymorphism has been associated with different diseases, such as hepatic cirrhosis [25], gastritis, gastric cancer [26], Type 2 diabetes mellitus [27] and inflammatory-autoimmune diseases, such as ankylosing spondylitis [28], systemic lupus erythematosus [29] and rheumatoid arthritis [30]. With regard to respiratory diseases, Kumar $e t$ al. found an association between the same polymorphism and bronchial asthma in an Indian population [31].

TNF- $\alpha$ serum levels were found to be increased in asthmatic patients compared with those in the AERD and HC groups. This finding may be due to the therapeutic control being different between both patient groups, and as a consequence, the inflammation biomarkers are controlled in AERD; this result has been reported by Baraket et al., who demonstrated a decrease in TNF- $\alpha$ concentrations in a bronchioalveolar wash after treatment with inhaled fluticasone propionate in asthmatic patients [32]. Varela et al. reported a similar finding in cultivating fibroblasts from nasal polyps, which, upon exposure to this steroid, inhibit the synthesis of cellular adhesion molecules [33]. In a similar model, Silvestri et al. reported a decrease in the expression of ICAM-1, but not VCAM-1, in the presence of TNF- $\alpha$ [34]. Together, these mechanisms lead to an improvement in pulmonary function and a decrease 
in the degree of nasal polyposis [35]. Patients with AERD who were treated in our clinic underwent a homogeneous treatment based on intranasal and inhaled fluticasone, the adherence to which was supervised approximately every 12 weeks. In comparison, patients with asthma were attended at different pneumological clinics, which use various treatment plans to control symptoms. This difference is a limiting factor in terms of controls for our study; this epidemiological phenomenon has already been studied and reported as a variable that can influence adherence to treatment and, therefore, can have repercussions on the levels of TNF- $\alpha$ [36]. To avoid these possible confounding factors, it is desirable to integrate patient groups with recent onset and administrate an established treatment of inhaled steroids; however, given that the onset age of AERD occurs at approximately 30 years, whereas asthmatics can be diagnosed from 6 years old, this is a difficult clinical characteristic to control. Another limitation of our study is that we were just be able to identify a genetic association with one SNP (rs 1800629) and its implication to the risk, which was associated by allele, codominant and recessive models. Through these methods, we showed the importance of the principal finding (allele A and its addition in 'double dose') by chi-square test. We think that using Bonferroni test or other statistical methods for correction (in this case bi-allelic model between two groups) could overcorrect the p-value. In addition, AERD is a complex disease with criteria that make its diagnosis difficult, and even though sample size is small, our group of specialists ensure patients phenotyping. Finally, it is necessary to replicate our findings in other populations, particularly among mestizos, in addition to completing functional trials and expression trials that corroborate the described findings.

\section{Conclusion}

The GA genotype of rs1800629 in TNF gene is associated with genetic susceptibility to AERD, but it does not correlate to protein serum levels.

\section{Future perspective}

Genetic association studies have been focused to provide information on the genotype frequency of SNPs candidate genes for complex diseases, such as AERD, and seek to know the expression of gene or protein. In this study, we found association between SNPs of TNF and susceptibility to AERD. On the other hand, we did not observe TNF protein levels associated with AERD. In the future, next studies should include other population, particularly among Latin-Americans mestizos, in order to replicate our findings.

\section{Executive summary}

- Polymorphism of the TNF gene is associated with risk of aspirin-exacerbated respiratory disease in the Mexican mestizo population.

- There is no correlation between genotypes of TNF and protein serum level.

- Our study provides the knowledge that polymorphisms in proinflammatory cytokine, such as TNF- $\alpha$, influence the development of aspirin-exacerbated respiratory disease.

Supplementary data

To view the supplementary data that accompany this paper please visit the journal website at: https://www.futuremedicine.com/doi/suppl/10.2217/bmm-2017-0164

Financial \& competing interests disclosure

The authors have no relevant affiliations or financial involvement with any organization or entity with a financial interest in or financial conflict with the subject matter or materials discussed in the manuscript. This includes employment, consultancies, honoraria, stock ownership or options, expert testimony, grants or patents received or pending, or royalties.

No writing assistance was utilized in the production of this manuscript.

Ethical conduct of research

The study was approved by the Science and Bioethics Committee of INER (protocol B14-12), and informed consent was obtained from all participants. 
Preliminary Communication Pavón-Romero, Reséndiz-Hernández, Ramírez-Jiménez et al.

Open access

This work is licensed under the Attribution-NonCommercial-NoDerivatives 4.0 Unported License. To view a copy of this license, visit http://creativecommons.org/licenses/by-nc-nd/4.0/

Author contributions

Study planning has been done by R Falfán-Valencia and GF Pavón-Romero. Data collection and interpretation of result have been done by GF Pavón-Romero, JM Reséndiz-Hernández and F Ramírez-Jiménez. R Falfán-Valencia, GF Pavón-Romero, G Pérez-Rubio, F Ramírez-Jiménez, A Camarena and LM Terán have written or critically revised the manuscript. All authors read and approved the final manuscript. Partial data of this manuscript will be presented in abstract form at national conference (Mexican Society of Pneumology and Thorax Surgery) on 17-21 April 2017.

\section{References}

Papers of special note have been highlighted as: $\bullet$ of interest; $\bullet \bullet$ of considerable interest

1 Jenkins C, Costello J, Hodge L. Systematic review of prevalence of aspirin induced asthma and its implications for clinical practice. BMJ 328, 434 (2004).

2 Mascia K, Haselkorn T, Deniz YM et al. Aspirin sensitivity and severity of asthma: evidence for irreversible airway obstruction in patients with severe or difficult-to-treat asthma. J. Allergy Clin. Immunol. 116, 970-975 (2005).

3 Mascia K, Borish L, Patrie J, Hunt J, Phillips CD, Steinke JW. Chronic hyperplastic eosinophilic sinusitis as a predictor of aspirin-exacerbated respiratory disease. Ann. Allergy Asthma Immunol. 94, 652-657 (2005).

4 Chang HS, Park JS, Jang AS et al. Diagnostic value of clinical parameters in the prediction of aspirin-exacerbated respiratory disease in asthma. Allergy Asthma Immunol. Res. 3, 256-264 (2011).

5 Szczeklik A, Sanak M. The broken balance in aspirin hypersensitivity. Eur. J. Pharmacol. 533, 145-155 (2006).

6 Kim SH, Park HS. Pathogenesis of nonsteroidal antiinflammatory drug-induced asthma. Curr. Opin. Allergy Clin. Immunol. 6, 17-22 (2006).

7 Brightling C, Berry M, Amrani Y. Targeting TNF- $\alpha$ : a novel therapeutic approach for asthma. J. Allergy Clin. Immunol. 121, 5-10 (2008).

8 Wouters EF, Reynaert NL, Dentener MA, Vernooy JH. Systemic and local inflammation in asthma and chronic obstructive pulmonary disease: is there a connection? Proc. Am. Thorac. Soc. 6, 638-647 (2009).

9 Mukhopadhyay S, Hoidal JR, Mukherjee TK. Role of TNFa in pulmonary pathophysiology. Respir. Res. 7, 125 (2006).

10 Wilson AG, Symons JA, McDowell TL, McDevitt HO, Duff GW. Effects of a polymorphism in the human tumor necrosis factor alpha promoter on transcriptional activation. Proc. Natl Acad. Sci. USA 94, 3195-3199 (1997).

11 Wu WS, McClain KL. DNA polymorphisms and mutations of the tumor necrosis factor- $\alpha$ (TNF- $\alpha$ ) promoter in Langerhans cell histiocytosis (LCH). J. Interf. Cytokine Res. 17, 631-635 (1997).

12 Jardim MJ, Dailey L, Silbajoris R, Diaz-Sanchez D. Distinct microRNA expression in human airway cells of asthmatic donors identifies a novel asthma-associated gene. Am. J. Respir. Cell Mol. Biol. 47, 536-542 (2012).

- Molecular network analysis indicated that putative targets were principally involved in regulating the expression of inflammatory pathway genes.

13 Waserman S, Nair P, Snider D et al. Local and systemic immunological parameters associated with remission of asthma symptoms in children. Allergy Asthma Clin. Immunol. 8, 16 (2012).

14 Crapo RO, Casaburi R, Coates AL et al. Guidelines for methacholine and exercise challenge testing-1999. This official statement of the American Thoracic Society was adopted by the ATS Board of Directors, July 1999. Am. J. Respir. Crit. Care Med. 161, 309-329 (2000).

15 Pérez-Padilla R, Valdivia G, Muiño A et al. Spirometric reference values in 5 large Latin American cities for subjects aged 40 years or over. Arch. Bronconeumol. English Ed. 42, 317-325 (2006).

16 Nizankowska-Mogilnicka E, Bochenek G, Mastalerz L et al. EAACI/GA2LEN guideline: aspirin provocation tests for diagnosis of aspirin hypersensitivity. Allergy 62, 1111-1118 (2007).

17 Fahrenholz JM. Natural history and clinical features of aspirin-exacerbated respiratory disease. Clin. Rev. Allergy Immunol. 24, 113-124 (2003).

18 Sabry EY. The prevalence of aspirin-induced asthma in Saudian asthmatic patients. Allergol. Immunopathol. (Madr.) 38, 181-186 (2010).

19 Li YF, Gauderman WJ, Avol E, Dubeau L, Gilliland FD. Associations of tumor necrosis factor G-308A with childhood asthma and wheezing. Am. J. Respir. Crit. Care Med. 173, 970-976 (2006).

20 Fuertes E, Brauer M, MacIntyre E et al. Childhood allergic rhinitis, traffic-related air pollution, and variability in the GSTP1, TNF, TLR2, and TLR4 genes: results from the TAG Study. J. Allergy Clin. Immunol. 132, 342.e2-352.e2 (2013). 
21 Jiménez-Morales S, Velázquez-Cruz R, Ramírez-Bello J et al. Tumor necrosis factor- $\alpha$ is a common genetic risk factor for asthma, juvenile rheumatoid arthritis, and systemic lupus erythematosus in a Mexican pediatric population. Hum. Immunol. 70, 251-256 (2009).

22 Falfán-Valencia R, Pavón-Romero GF, Camarena A et al. The IL1B-511 polymorphism (rs16944 AA genotype) is increased in aspirin-exacerbated respiratory disease in Mexican population. J. Allergy 2012, 1-5 (2012).

-. This is the first observation that genetic polymorphisms in proinflammatory cytokines are involved in aspirin-exacerbated respiratory disease. In addition, this is the only work in a population different to Asian or Caucasian population looking for genetic factors involved in aspirin-exacerbated respiratory disease susceptibility.

23 Wilson AG, di Giovine FS, Blakemore AI, Duff GW. Single base polymorphism in the human tumour necrosis factor alpha (TNF alpha) gene detectable by NcoI restriction of PCR product. Hum. Mol. Genet. 1, 353 (1992).

24 D'Alfonso S, Richiardi PM. A polymorphic variation in a putative regulation box of the TNFA promoter region. Immunogenetics 39 , 150-154 (1994).

25 Dutta AK. Genetic factors affecting susceptibility to alcoholic liver disease in an Indian population. Ann. Hepatol. 12, 901-907 (2013).

26 Li M, Wang Y, Gu Y. Quantitative assessment of the influence of tumor necrosis factor alpha polymorphism with gastritis and gastric cancer risk. Tumor Biol. 35, 1495-1502 (2014).

27 Liu ZH, Ding YL, Xiu LC et al. A meta-analysis of the association between TNF- $\alpha-308 \mathrm{G}>$ A polymorphism and Type 2 diabetes mellitus in Han Chinese population. PLoS ONE 8, e59421 (2013).

28 Sun R, Huang Y, Zhang H, Liu R. MMP-2, TNF- $\alpha$ and NLRP1 polymorphisms in Chinese patients with ankylosing spondylitis and rheumatoid arthritis. Mol. Biol. Rep. 40, 6303-6308 (2013).

29 Lee YH, Bae SC, Choi SJ, Ji JD, Song GG. Genome-wide pathway analysis of genome-wide association studies on systemic lupus erythematosus and rheumatoid arthritis. Mol. Biol. Rep. 39, 10627-10635 (2012).

30 Toonen EJ, Barrera P, Fransen J et al. Meta-analysis identified the TNFA -308G > A promoter polymorphism as a risk factor for disease severity in patients with rheumatoid arthritis. Arthritis Res. Ther. 14, R264 (2012).

31 Kumar V, Khosla R, Gupta V, Sarin BC, Sehajpal PK. Differential association of tumour necrosis factor-alpha single nucleotide polymorphism (-308) with tuberculosis and bronchial asthma. Natl Med. J. India 21, 120-122 (2008).

32 Baraket M, Oliver BG, Burgess JK, Lim S, King GG, Black JL. Is low dose inhaled corticosteroid therapy as effective for inflammation and remodeling in asthma? A randomized, parallel group study. Respir. Res. 13, 11 (2012).

33 Valera F, Brassesco MS, Castro-Gamero AM. In vitro effect of glucocorticoids on nasal polyps. Braz. J. Otorhinolaryngol. 77, 605-610 (2011).

34 Silvestri M, Sabatini F, Scarso L, Cordone A, Dasic G, Rossi GA. Fluticasone propionate downregulates nasal fibroblast functions involved in airway inflammation and remodeling. Int. Arch. Allergy Immunol. 128, 51-58 (2002).

35 Holmberg K, Juliusson S, Balder B, Smith DL, Richards DH, Karlsson G. Fluticasone propionate aqueous nasal spray in the treatment of nasal polyposis. Ann. Allergy Asthma Immunol. 78, 270-276 (1997).

36 Williams LK, Pladevall M, Xi H, Peterson EL, Joseph C, Lafata JE. Relationship between adherence to inhaled corticosteroids and poor outcomes among adults with asthma. J. Allergy Clin. Immunol. 114, 1288-1293 (2004). 
(

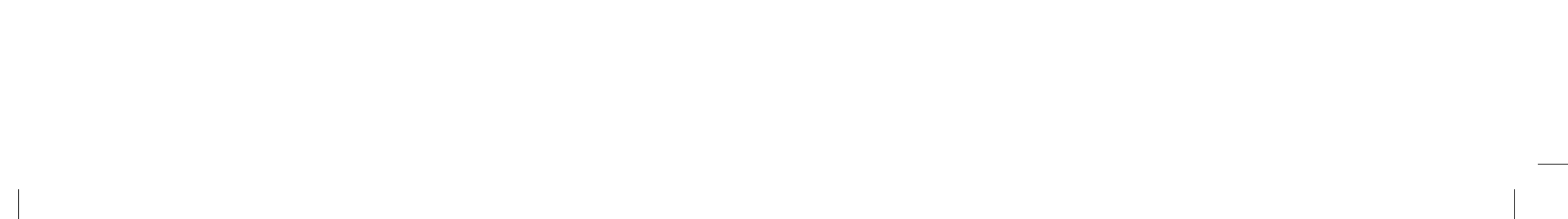

